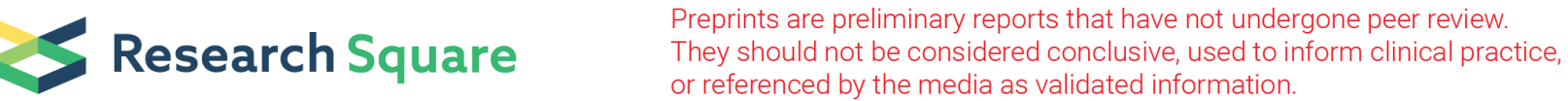

\section{The Effects of Oral fat Based High-Energy Supplements on Nutritional and Inflammatory Status in Maintenance Hemodialysis Patients}

mingming Pan

Southeast University Zhongda Hospital

Min Gao

Southeast University Zhongda Hospital

Jing Zheng

Southeast University Zhongda Hospital

Jirong Yu

Southeast University Zhongda Hospital

Sheng-chun Xu

Southeast University Zhongda Hospital

Mei-xia Xia

Southeast University Zhongda Hospital

Wen-jie Liu

Southeast University School of Economics and Management

Liu-ping Zhang

Southeast University Zhongda Hospital

Xiao-liang Zhang

Southeast University Zhongda Hospital

Bi-cheng Liu

Southeast University Zhongda Hospital

Jing-yuan Cao

Jiangsu Taizhou People's Hospital

Bin Wang ( $\nabla$ wangbinhewei@126.com )

Southeast University Zhongda Hospital

\section{Research}

Keywords: Fresubin, malnutrition, inflammation, hemodialysis

Posted Date: January 18th, 2022

DOI: https://doi.org/10.21203/rs.3.rs-1221289/v1 
License: (c) (i) This work is licensed under a Creative Commons Attribution 4.0 International License. Read Full License 


\section{Abstract}

Background: Protein-energy wasting (PEW) and inflammation have been recognized as two major factors associated with the poor prognosis of patients with maintenance haemodialysis (MHD). The aim of this study was to evaluate the effects of oral fat based high-energy supplements (Fresubin) on malnutrition and inflammation in MHD patients.

Method: This study was open-label, prospective, nonrandomized and comparative. A total of $47 \mathrm{MHD}$ patients with PEW were randomly assigned into 2 groups: a control group, and a Fresubin treatment group, in which patients received daily diet intake and Fresubin nutrient support $120 \mathrm{~mL} / \mathrm{d}$ for 80 days. Laboratory data and anthropometric parameters were measured.

Result: The results showed that compared with baseline, the level of serum albumin at $80 \mathrm{~d}$ in the Fresubin treatment group was significantly increased $(35.4 \pm 3.7 v s 38.9 \pm 2.9, p=0.003)$, while there was no significant difference in the control group. In addition, the magnitudes of changes in albumin $(p=$ $0.009)$, serum prealbumin $(p=0.017)$, and abdominal circumference $(p=0.037)$ in the Fresubin treatment group were markedly increased compared with those in the control group. There was a downward trend in the inflammatory marker hypersensitive $C$-reactive protein in the Fresubin group $(p=0.056)$, which decreased more dramatically than that in the control group $(p=0.026)$.

Conclusion: Fresubin treatment is well tolerated, and improves malnutrition and inflammatory status in MHD patients with PEW.

\section{Introduction}

In patients with end-stage renal disease (ESRD), inadequate nutrient energy intake is often observed [1, 2]. The term "Protein-energy wasting" (PEW), characterized by declines in body protein mass and energy reserves, is common concept that reflects nutritional status in patients with ESRD [3]. Inadequate protein and energy intake were tightly linked to PEW in maintenance haemodialysis (MHD) patients [4, 5]. The HEMO study showed that low values of protein and energy intake were associated with indexes of comorbidity, especially in older patients [4]. Araujo et al demonstrated that energy intake was an independent predictor of 10-year mortality in MHD patients [5]. Growing evidence has indicated that PEW and inflammation contribute to quality of life and high mortality in MHD patients $[3,6,7]$.Therefore, the interventions to ameliorate nutritional status and inflammation are crucial.

Individualized nutritional support, an optimized dialysis regime and the management of comorbidities (e.g., infection, metabolic acidosis, heart failure, and depression) are the most essential methods for managing ESRD $[8,9]$. The guidelines strong recommended nutritional interventions in MHD patients [10]. However, evidence regarding the effects of oral nutritional supplements (ONS) on the nutritional status of MHD patients is insufficient and inconsistent [11-14]. Most of the ONS used in previous studies were amino acid or protein-based supplements. Although protein and amino acids supplementation may be effective in improving PEW in MHD patients, the risk for metabolic waste (hyperphosphatemia, 
hyperureaemia) can be substantial and should be carefully monitored [15-17]. Previous prospective cohort studies have suggested that total fat and individual types of fat were related to lower total mortality [18]. However, the effects of oral fat based high-energy supplements on the nutritional status and inflammation of MHD patients was largely unknown. Fresubin is an oral high-energy nutrient solution with a fat content of $53.8 \mathrm{~g} / 100 \mathrm{~mL}$ that is rich in polyunsaturated fatty acids $(12.5 \mathrm{~g} / 100 \mathrm{~mL})$ and free of phosphorus, potassium and protein. In the present study, we evaluated the effects of Fresubin treatment on nutritional and inflammatory status in MHD patients.

\section{Methods}

\subsection{Research participants}

This study was open-label, prospective, nonrandomized and comparative. It was performed at an outpatient hemodialysis center in a teaching hospital. Approval from the ethics committees of Zhongda Hospital, Southeast University School of Medicine was obtained before subject recruitment (2019ZDSYLL146-P01).

All patients ( $>18 \mathrm{y})$ were treated and received MHD for at least 3 months at our hospital. Patients were undergoing 4- to 4.5-h dialysis sessions 3 times per week. The blood flow rate ranged from 200 to 250 $\mathrm{mL} / \mathrm{min}$, and bicarbonate buffer was used. A 3-day diet record (one day of haemodialysis, 2 days of nonhaemodialysis) was used to assess the participant's nutritional intake. According to the PEW diagnostic criteria recommended by the International Society of Renal Nutrition and Metabolism (ISRNM) [19], the inclusion criteria for this study were as follows: 1 ) serum albumin (Alb) $<38 \mathrm{~g} / \mathrm{L}$ or serum prealbumin $(\mathrm{PA})<0.3 \mathrm{~g} / \mathrm{L} ; 2)$ body mass index (BMI) $<23 \mathrm{~kg} / \mathrm{m}^{2}$; and 3) dietary protein intake (DPI) $<0.8 \mathrm{~g} / \mathrm{kg} / \mathrm{day}$. Patients had to meet any 2 of the above 3 conditions for inclusion in the study. Exclusion criteria: 1) gastrointestinal bleeding and an inability to eat; 2) serious infection and severe wasting diseases; 3 ) liver failure and cirrhosis; 4) cancer; 5) acute phase of disease; 6) not signed an informed consent; and 7) incomplete information. The flowchart was displayed in Figure 1.

A total of 47 patients were involved in this study from August to December, 2019. They were allocated to 2 groups based on subject preference: 1) control group, in which patients received daily diet intake only; and 2) Fresubin treatment group, in which patients received daily diet intake and Fresubin nutrition support $120 \mathrm{~mL} / \mathrm{d}$ for 80 days. Fresubin (Fresenius Kabi Deutschland, Germany) was chosen because it was the formulary supplement prescribed to meet the nutritional needs (supplement $600 \mathrm{kcal}$ energy) of patients receiving dialysis. The dosage is $120 \mathrm{~mL}$ per day, divided into two to three times after meal.

\subsection{Laboratory data}

Blood samples were collected for at least 10-h fast and after an HD session respectively. Biochemical parameters, including haemoglobin $(\mathrm{Hb})$, blood urea nitrogen $(\mathrm{BUN})$, serum creatinine $(\mathrm{Scr})$, Alb, PA, total cholesterol $(\mathrm{CHO})$, triglyceride $(\mathrm{TG})$, serum potassium $(\mathrm{K})$, calcium $(\mathrm{Ca})$, phosphate $(\mathrm{P})$, glucose $(\mathrm{Glu})$, serum ferritin (SF) and hypersensitive C-reactive protein (Hs-CRP), were obtained with routine laboratory 
methods in clinical laboratory of Zhongda Hospital within 4 hours of blood collection. The adequacy of dialysis (Kt/V) was determined according to the Daugirdas method.

\subsection{Anthropometric parameter assessment}

Anthrometric measurements were obtained after haemodialysis (15 to 30 minutes). BMI was calculated using dry weight. Triceps-skinfold thickness (TSF) was measured using a conventional skinfold calliper with standard techniques, and the mid-arm circumference (MAC) and abdominal circumference (AC) were measured using plastic tape. Grip strength (GS) was measured using the same dynamometer with the hand on the non-fistula side. All the above parameters were tested 3 times, and the averages were taken.

\subsection{Study outcomes}

The primary clinical outcome of interest was change in nutritional status (Alb, PA, $\mathrm{Hb}$ ) over the study period (80 days). The secondary clinical outcomes were inflammatory status, other laboratory markers and anthropometric parameters.

\subsection{Statistical Analysis}

Statistical analyses were performed using SPSS 20.0 software. The data are given as the mean \pm SD for normally distributed variables and as the median and interquartile range for non-normally distributed variables. Univariate analyses were performed to compare the differences between two groups. All analyses were two-tailed, and a $P$ value $<0.05$ was considered to be statistically significant.

\section{Results}

\subsection{Baseline patient characteristics}

Our study enrolled 47 participants: 22 in Fresubin treatment group and 25 in control group. Finally, 20 (91\%) participants in Fresubin treatment group and 25 (100\%) participants in the control group completed 80 days testing and were included in the complete case analyses. 2 participants from treatment group withdrew because they did not like the taste of Fresubin.

The baseline characteristics of the two groups were compared (Table 1). The mean ages were $58 \pm 15$ and $59 \pm 16$ years in the Fresubin treatment and control groups, respectively $(p=0.825)$. There were no significant differences in dry weight $(60.3 \pm 14.2$ vs $63.2 \pm 8.6, p=0.399)$ or BMl $(21.32 \pm 3.83$ vs $22.39 \pm$ $2.46, p=0.264)$ at the beginning of the study. The dietary energy intake $(28.74 \pm 2.83$ vs $28.91 \pm 3.58, p=$ $0.868)$ and dietary protein intake $(0.84(0.77,0.96)$ vs $0.77(0.73,0.90), p=0.102)$ between two groups had no significant differences. There were also no significant differences in any baseline clinical or nutritional parameters between the two groups (Table 1). 
Table 1

Basic data of the patients between Fresubin and control groups

\begin{tabular}{|c|c|c|c|}
\hline Od & $\begin{array}{l}\text { Fresubin treatment group }(n= \\
\text { 20) }\end{array}$ & $\begin{array}{l}\text { Control group }(n= \\
25)\end{array}$ & $P$ \\
\hline Age (y) & $58 \pm 15$ & $59 \pm 16$ & 0.825 \\
\hline sex(male) & $14(63.6 \%)$ & $13(52.0 \%)$ & 0.380 \\
\hline Dry weight (kg) & $60.3 \pm 14.2$ & $63.2 \pm 8.6$ & 0.399 \\
\hline BMI $\left(\mathrm{kg} / \mathrm{m}^{2}\right)$ & $21.32 \pm 3.83$ & $22.39 \pm 2.46$ & 0.264 \\
\hline Dialysis time (month) & $66.5(38,89)$ & $64(53,98)$ & 0.495 \\
\hline Etiology of ESRD & & & 0.455 \\
\hline Diabetes & $6(27.3 \%)$ & $7(28.0 \%)$ & \\
\hline Hypertension & $7(31.8 \%)$ & $7(28.0 \%)$ & \\
\hline Glomerulonephritis & $6(27.3 \%)$ & $7(28.0 \%)$ & \\
\hline Polycystic kidney & $2(9.0 \%)$ & $3(12.0 \%)$ & \\
\hline Other & $1(4.5 \%)$ & $1(4.0 \%)$ & \\
\hline $\mathrm{Hb}(\mathrm{g} / \mathrm{L})$ & $112 \pm 17$ & $106 \pm 21$ & 0.332 \\
\hline Alb $(g / L)$ & $35.4 \pm 3.7$ & $37.0 \pm 2.3$ & 0.108 \\
\hline $\mathrm{PA}(\mathrm{g} / \mathrm{L})$ & $0.29 \pm 0.08$ & $0.28 \pm 0.07$ & 0.839 \\
\hline $\mathrm{K}(\mathrm{mmol} / \mathrm{L})$ & $4.62 \pm 0.68$ & $4.46 \pm 0.69$ & 0.443 \\
\hline $\mathrm{Ca}(\mathrm{mmol} / \mathrm{L})$ & $2.29 \pm 0.18$ & $2.22 \pm 0.19$ & 0.215 \\
\hline $\mathrm{P}(\mathrm{mmol} / \mathrm{L})$ & $1.87 \pm 0.48$ & $1.71 \pm 0.48$ & 0.262 \\
\hline BUN (mmol/L) & $26.50(21.23,28.78)$ & $22.70(18.90,27.65)$ & 0.184 \\
\hline $\mathrm{SCr}(\mu \mathrm{mol} / \mathrm{L})$ & $790.0(736.3,1124.5)$ & $\begin{array}{l}899.0(604.0 \\
1010.0)\end{array}$ & 0.506 \\
\hline TG (mmol/L) & $1.80 \pm 0.86$ & $1.97 \pm 1.55$ & 0.661 \\
\hline Glu (mmol/L) & $7.59 \pm 4.25$ & $8.17 \pm 4.68$ & 0.670 \\
\hline $\mathrm{CHO}(\mathrm{mmol} / \mathrm{L})$ & $3.84 \pm 1.30$ & $4.16 \pm 0.81$ & 0.304 \\
\hline $\mathrm{SF}(\mu \mathrm{g} / \mathrm{L})$ & $209.4 \pm 311.8$ & $221.4 \pm 224.7$ & 0.883 \\
\hline \multicolumn{4}{|c|}{$\begin{array}{l}\text { BMI, body mass index; Hb, heamoglobin; Alb, albumin; PA, prealbumin; K, potassium; Ca, calcium; P, } \\
\text { phosphate; BUN, blood urea nitrogen; Scr, serum creatinine; UF, ultra filtration; TG, triglyceride; Glu, } \\
\text { serum glucose; CHO, total cholesterol; SF, serum ferritin; HS-CRP, hypersensitive C-reactive protein; } \\
\text { Kt/V, adequacy of dialysis; GS, grip strength; MAC, mid arm circumference; AC, abdominal } \\
\text { circumference; TSF, triceps-skinfold thickness. }\end{array}$} \\
\hline
\end{tabular}




\begin{tabular}{|c|c|c|c|}
\hline Od & $\begin{array}{l}\text { Fresubin treatment group }(n= \\
\text { 20) }\end{array}$ & $\begin{array}{l}\text { Control group }(n= \\
25)\end{array}$ & $P$ \\
\hline Hs-CRP (mg/L) & $3.66(0.82,9.87)$ & $3.60(0.82,6.31)$ & 0.399 \\
\hline UF (L) & $2.0(1.8,2.5)$ & $2.5(1.6,3.0)$ & 0.293 \\
\hline $\begin{array}{l}\text { Dietary energy intake, } \\
\mathrm{kcal} / \mathrm{IBW} / \mathrm{d}\end{array}$ & $28.74 \pm 2.83$ & $28.91 \pm 3.58$ & 0.868 \\
\hline Dietary protein intake, $\mathrm{g} / \mathrm{IBW} / \mathrm{d}$ & $0.84(0.77,0.96)$ & $0.77(0.73,0.90)$ & 0.102 \\
\hline $\mathrm{Kt} / \mathrm{V}$ & $1.21 \pm 0.26$ & $1.17 \pm 0.23$ & 0.599 \\
\hline $\mathrm{GS}(\mathrm{N} / \mathrm{m})$ & $24.45 \pm 11.49$ & $20.80 \pm 7.20$ & 0.226 \\
\hline MAC (cm) & $26.62 \pm 3.58$ & $26.56 \pm 4.09$ & 0.960 \\
\hline$A C(\mathrm{~cm})$ & $85.18 \pm 16.59$ & $90.82 \pm 9.70$ & 0.161 \\
\hline TSF (mm) & $20.40 \pm 6.17$ & $18.60 \pm 8.18$ & 0.420 \\
\hline \multicolumn{4}{|c|}{$\begin{array}{l}\text { BMI, body mass index; Hb, heamoglobin; Alb, albumin; PA, prealbumin; K, potassium; Ca, calcium; P, } \\
\text { phosphate; BUN, blood urea nitrogen; Scr, serum creatinine; UF, ultra filtration; TG, triglyceride; Glu, } \\
\text { serum glucose; CHO, total cholesterol; SF, serum ferritin; Hs-CRP, hypersensitive C-reactive protein; } \\
\text { Kt/V, adequacy of dialysis; GS, grip strength; MAC, mid arm circumference; AC, abdominal } \\
\text { circumference; TSF, triceps-skinfold thickness. }\end{array}$} \\
\hline
\end{tabular}

\subsection{Fresubin improves serum Alb levels in MHD patients}

After 80 days intervention, the level of Alb was significantly increased compared with baseline in the Fresubin treatment group (35.4 \pm 3.7 vs $38.9 \pm 2.9, p=0.003)$, while there was no significant difference in the control group $(37.0 \pm 2.3$ vs $37.3 \pm 2.6, p=0.656)$. The serum PA concentration was much higher after intervention in Fresubin treatment group $(0.29 \pm 0.08$ vs $0.33 \pm 0.07, p=0.095)$, but the difference was not statistically significant. Other biochemical indexes (such as $\mathrm{K}, \mathrm{Ca}, \mathrm{P}, \mathrm{CHO}$ and $\mathrm{TG}$ ) and anthropometric parameters were almost the same compared with baseline in both groups (Table 2). Additionally, as shown in Figure 2, the level of Alb increased significantly at 30 days compared with baseline $(p=0.003)$, and the increase continued until the end of the study $(p=0.003)$. 
Table 2

The data of patients on Fresubin and control groups from 0 and 80day

Fresubin group $(n=20)$

Od

$60.3 \pm 14.2$

Dry

$(\mathrm{kg})$

$\mathrm{BMI}$

$21.32 \pm 3.83$

$21.72 \pm 3.84$

$61.4 \pm 14.3$

80d $\quad P$

Od

0.818

$63.2 \pm 8.6$

80d

$61.2 \pm 11.4$

0.474

$\left(\mathrm{kg} / \mathrm{m}^{2}\right)$

$\mathrm{Hb}(\mathrm{g} / \mathrm{L})$

$112 \pm 17$

$117 \pm 13$

$0.297 \quad 106 \pm 21$

$111 \pm 18$

0.448

Alb $(\mathrm{g} / \mathrm{L}) \quad 35.4 \pm 3.7$

$38.9 \pm 2.9$

$0.003 \quad 37.0 \pm 2.3$

$37.3 \pm 2.6$

0.656

$\mathrm{PA}(\mathrm{g} / \mathrm{L})$

$0.29 \pm 0.08$

$0.33 \pm 0.07$

$0.095 \quad 0.28 \pm 0.07$

$0.29 \pm 0.06$

0.816

K

(mmol/L)

$4.62 \pm 0.68$

$4.72 \pm 0.63$

0.660

$4.46 \pm 0.69$

$4.54 \pm 0.52$

0.669

$\mathrm{Ca}$

$2.29 \pm 0.18$

$2.85 \pm 2.27$

$0.284 \quad 2.22 \pm 0.19$

$2.26 \pm 0.20$

0.439

(mmol/L)

$\mathrm{P}$
$(\mathrm{mmol} / \mathrm{L})$

$1.87 \pm 0.48$

$1.87 \pm 0.56$

$0.985 \quad 1.71 \pm 0.48$

$1.74 \pm 0.46$

0.792

BUN

$(\mathrm{mmol} / \mathrm{L})$

$\mathrm{SCr}$

$(\mu \mathrm{mol} / \mathrm{L})$

$\begin{array}{lll}\text { TG } & 1.80 \pm 0.86 & 1.85 \pm 0.85\end{array}$

$(\mathrm{mmol} / \mathrm{L})$

Glu

$(\mathrm{mmol} / \mathrm{L})$

$26.75(22.33$,

25.19 (23.68,

26.80)

0.351

28.93)

790.0 (736.3,

$775.6(772.0$,

796.0)

$8.01 \pm 4.11$

$7.59 \pm 4.25$

$3.84 \pm 1.30$

$4.11 \pm 1.06$

$\mathrm{CHO}$
$(\mathrm{mmol} / \mathrm{L})$

$\operatorname{SF}(\mu \mathrm{g} / \mathrm{L}) \quad 209.4 \pm 311.8 \quad 243.2 \pm 293.0$

$0.82(0.82,1.90)$

$3.66(0.82$,

Hs-CRP
(mg/L)

9.87)

GS $(\mathrm{N} / \mathrm{m}) \quad 24.45 \pm 11.49$

$25.17 \pm 10.10$

0.836

0.602

0.757

0.476

$22.70(18.90$, 27.65)

899.0 (604.0,

1010.0)

$0.854 \quad 1.97 \pm 1.55 \quad 2.06 \pm 1.37$

$4.16 \pm 0.81$

$4.10 \pm 0.83$

0.769

$8.17 \pm 4.68$

$7.57 \pm 3.15$

0.600

$24.00(21.20, \quad 0.756$ 28.90)

$877.3(681.5$,

0.726

1004.3)

0.838 


\begin{tabular}{|c|c|c|c|c|c|c|}
\hline \multirow[b]{2}{*}{ MAC (cm) } & \multicolumn{2}{|c|}{ Fresubin group $(n=20)$} & \multicolumn{3}{|c|}{ Control group $(n=25)$} & \multirow[b]{2}{*}{0.790} \\
\hline & $26.62 \pm 3.58$ & $27.47 \pm 3.61$ & 0.460 & $26.56 \pm 4.09$ & $26.26 \pm 3.72$ & \\
\hline $\mathrm{AC}(\mathrm{cm})$ & $85.18 \pm 16.59$ & $86.90 \pm 15.91$ & 0.743 & $90.82 \pm 9.70$ & $90.34 \pm 9.25$ & 0.859 \\
\hline TSF (mm) & $20.40 \pm 6.17$ & $21.55 \pm 5.37$ & 0.538 & $18.60 \pm 8.18$ & $19.22 \pm 7.49$ & 0.782 \\
\hline \multicolumn{7}{|c|}{$\begin{array}{l}\text { BMI, body mass index; } \mathrm{Hb} \text {, heamoglobin; Alb, albumin; PA, prealbumin; } \mathrm{K} \text {, potassium; Ca, calcium; } \mathrm{P} \text {, } \\
\text { phosphate; BUN, blood urea nitrogen; Scr, serum creatinine; TG, triglyceride; Glu, serum glucose; } \mathrm{CHO} \text {, } \\
\text { total cholesterol; SF, serum ferritin; Hs-CRP, hypersensitive C-reactive protein; GS, grip strength; MAC, } \\
\text { mid arm circumference; AC, abdominal circumference; TSF, triceps-skinfold thickness. }\end{array}$} \\
\hline
\end{tabular}

\subsection{Fresubin improves nutritional and inflammatory status in MHD patients}

We also compared the change values between the two groups from 0 to 80 days and found that the changes in the biochemical indexes Alb and PA in the Fresubin treatment group were markedly increased compared with those in the control group, and the differences were statistically significant $(p=0.009$ for Alb, $p=0.017$ for PA). We also found a significant decrease in the inflammatory marker Hs-CRP in the Fresubin treatment group compared with the change in the control group $(p=0.026)$. With the improvement of patients' nutritional status, the change in abdominal circumference was also increased in the Fresubin group compared with the control group $(p=0.037)$ (Table 3$)$. 
Table 3

The change values data of patients on Fresubin and control groups from 0 to 80 days

Fresubin treatment group $(n=20) \quad$ Control group $(n=25)$

\begin{tabular}{|c|c|c|c|}
\hline Dry weight (kg) & $0.5(0.0,0.8)$ & $0.0(0.0,0.4)$ & 0.077 \\
\hline BMI $\left(\mathrm{kg} / \mathrm{m}^{2}\right)$ & $0.16(0.02,0.25)$ & $0.03(-0.01,0.10)$ & 0.077 \\
\hline $\mathrm{Hb}(\mathrm{g} / \mathrm{L})$ & $3(-6,13)$ & $1(-5,10)$ & 0.927 \\
\hline Alb (g/L) & $3.1(0.0,5.3)$ & $0.3(-1.2,1.2)$ & 0.009 \\
\hline $\mathrm{PA}(\mathrm{g} / \mathrm{L})$ & $0.04 \pm 0.05$ & $0.00 \pm 0.05$ & 0.017 \\
\hline $\mathrm{K}(\mathrm{mmol} / \mathrm{L})$ & $0.08 \pm 0.77$ & $0.07 \pm 0.69$ & 0.976 \\
\hline $\mathrm{Ca}(\mathrm{mmol} / \mathrm{L})$ & $0.03(-0.09,0.11)$ & $0.03(-0.01,0.14)$ & 0.265 \\
\hline $\mathrm{P}(\mathrm{mmol} / \mathrm{L})$ & $-0.01 \pm 0.48$ & $0.04 \pm 0.33$ & 0.734 \\
\hline TG (mmol/L) & $0.01 \pm 0.93$ & $0.09 \pm 1.29$ & 0.829 \\
\hline Glu (mmol/L) & $0.61(-0.70,1.89)$ & $-0.32(-1.20,1.50)$ & 0.094 \\
\hline $\mathrm{CHO}(\mathrm{mmol} / \mathrm{L})$ & $0.27 \pm 0.82$ & $-0.07 \pm 0.71$ & 0.155 \\
\hline$S F(\mu g / L)$ & $37.0(8.2,120.8)$ & $0.0(-11.2,53.1)$ & 0.540 \\
\hline BUN (mmol/L) & $-0.05(-4.02,0.61)$ & $1.50(-1.80,2.20)$ & 0.185 \\
\hline $\operatorname{Scr}(\mu \mathrm{mol} / \mathrm{L})$ & $8.9(-173.6,53.6)$ & $-3.8(-77.8,124.0)$ & 0.362 \\
\hline Hs-CRP (mg/L) & $-0.90(-6.40,0.00)$ & $-0.75(0.00,0.17)$ & 0.026 \\
\hline $\mathrm{GS}(\mathrm{N} / \mathrm{m})$ & $2.00(-2.50,5.40)$ & $0.30(-1.00,1.45)$ & 0.471 \\
\hline $\mathrm{MAC}(\mathrm{cm})$ & $1.00(0.00,4.00)$ & $0.00(-0.85,0.10)$ & 0.142 \\
\hline $\mathrm{AC}(\mathrm{cm})$ & $1.50(-0.50,4.00)$ & $0.00(-0.75,0.00)$ & 0.037 \\
\hline TSF (mm) & $0.00(-1.00,4.00)$ & $0.00(-0.50,1.00)$ & 0.992 \\
\hline
\end{tabular}

BMI: body mass index; Hb: heamoglobin; Alb: albumin; PA: prealbumin; K: potassium; Ca: calcium;P: phosphate; TG: triglyceride; Glu: serum glucose; $\mathrm{CHO}$ : total cholesterol; SF: serum ferritin; BUN: blood urea nitrogen; Scr: serum creatinine; Hs-CRP: hypersensitive C-reactive protein; GS: grip strength; MAC: mid arm circumference; AC: abdominal circumference; TSF: triceps-skinfold thickness.

\section{Discussion}

Among the many risk factors that affect the outcomes of ESRD patients, especially MHD patients, nutritional deficiency plays a major role. The prevalence of malnutrition among MHD patients varies from $30-75 \%[20,21]$. In this study, we evaluated the effects of oral fat based high-energy supplements (Fresubin) on nutritional and inflammatory status in MHD patients. These findings suggested that 
Fresubin nutritional support could continuously and effectively improve the nutritional status and inflammation in MHD patients after 80 days intervention.

Inadequate dietary protein and energy intake levels are important causes of PEW in ESRD patients and may be caused by anorexia. Furthermore, there is additional nutritional loss during dialysis, such as amino acids, albumin and some trace elements, in the dialysate and inflammatory stimuli associated with the dialysis procedure [3]. The recommended daily protein and energy requirements for haemodialysis patients are $1.2 \mathrm{~g} / \mathrm{kg}$ of ideal body weight per day and 30-35 kcal/ $\mathrm{kg}$ of ideal body weight per day [22]. In fact, in many dialysis patients, the levels of protein and energy intake do not reach the recommended proper goals. The protein and energy intake of these research participants are both insufficient.

The ISRNM proposed 4 main categories to diagnose PEW: biochemical criteria, low body mass, decreased muscle mass and low protein intake [19]. Among biochemical indicators, serum albumin is a consistent indicator for PEW, and low serum albumin is one of the strongest predictors of mortality in MHD patients $[9,23]$. More importantly, a change in the serum level of Alb over time is associated with alterations in the risk of mortality, in that only a small increase or decrease in serum Alb concentration over a period of time is associated with increased or decreased survival, respectively [24, 25]. In this study, we treated patients who had poor nutrition status with an oral high-energy nutrient solution, Fresubin 120 $\mathrm{mL} /$ day, for 80 days and found that the level of Alb increased quickly and that the increase continued until the end of the study. Another nutritional marker, PA, also increased in the treatment group, and the difference in the change in PA between the two groups was significantly different.

There is an important consideration when we ask patients to improve their dietary intake or provide nutrition support. The potential increase in the intake of several harmful elements, especially phosphorus, is a troublesome clinical problem. Hyperphosphatemia is an independent risk factor for cardiovascular disease and death in patients with CKD $[26,27]$. Interestingly, the amount of dietary protein is usually correlated with phosphorus content and serum phosphorus concentration in ESRD patients. In adenineinduced CKD rats, a high-phosphorus diet was found to induce systemic inflammation and oxidative stress, resulting in the development of PEW, weight loss and hypoalbuminemia [28]. We need to find a method of compromise that does not increase phosphorus intake but improves the nutritional status of patients. Some foods with a low P/protein ratio should be suggested. In our test, we used the ONS Fresubin to improve the nutritional status of patients while improving the serum Alb without a significant effect on phosphorus. Fresubin treatment also had no effect on other biochemical indexes that we should closely monitor, such as blood lipids, Glu, K and Ca.

Inflammation is a major driving force for many uraemic complications, including PEW. Persistent, lowgrade inflammation has been recognized as a component of CKD [28]. Animal studies have shown that infusions of TNF, IL-1, and IL-6 cause increased muscle protein breakdown, resulting in muscle atrophy [29]. Clinical studies have shown that malnutrition, inflammation and atherosclerosis are closely related in patients with ESRD [30]. Our study found that the level of the inflammatory biomarker Hs-CRP tended 
to decrease after nutritional intervention, and the difference in the change value between the two groups was statistically significant. This phenomenon has also been observed in other nutritional interventions [31-33].

Anthropometric and body composition parameters are also independent predictors of mortality in haemodialysis patients [34]. Contrary to the general population, many studies in ESRD patients have reported a "reverse epidemiology", where higher BMI is paradoxically associated with better survival, especially among those with a higher muscle mass $[35,36]$. In our study, only the change value of AC was different between the two groups, with no significant differences in other parameters, which may be related to the short intervention time.

Throughout the study period, most patients in the treatment group were able to adhere to daily oral nutrient solution support, 2 patients developed nausea after taking Fresubin and withdrew, and 3 patients developed mild abdominal distension, but it resolved on its own. Fresubin therapy was well tolerated, and no other significant adverse reactions were observed.

This study has several limitations. First, the sample size was small. Second, the time interval between the two groups was short, and a longer follow-up period would yield more information.

\section{Conclusion}

The oral fat based high-energy supplements (Fresubin) were well tolerated and could effectively improve the nutritional and inflammation status in MHD patients with PEW.

\section{Abbreviations}

AC, abdominal circumference; Alb, albumin; BMI, body mass index; BUN, blood urea nitrogen; $\mathrm{Ca}$, calcium; $\mathrm{CHO}$, total cholesterol; DPI, dietary protein intake; ESRD, end-stage renal disease; Glu, glucose; GS, grip strength; $\mathrm{Hb}$, haemoglobin; Hs-CRP, hypersensitive C-reactive protein; ISRNM, International Society of Renal Nutrition and Metabolism; K, potassium; Kt/V, adequacy of dialysis; MAC, mid arm circumference; $\mathrm{MHD}$, maintenance hemodialysis; ONS, oral nutritional

\section{Declarations}

\section{Authors' information}

Ming-ming Pan ${ }^{a}$, Min Gao ${ }^{a}$, Jing Zheng ${ }^{b}$, Jirong Yua ${ }^{a}$, Sheng-chun Xua ${ }^{a}$, Mei-xia Xia ${ }^{a}$, Wen-jie Liua ${ }^{a}$ Liu-ping Zhang ${ }^{\mathrm{a}}$, Xiao-liang Zhang ${ }^{\mathrm{a}}$, Bi-cheng Liu ${ }^{\mathrm{a}}$, Jing-yuan Caoc,a, Bin Wang ${ }^{\mathrm{a}}$

a Institute of Nephrology, ${ }^{b}$ Department of Gerontology, Zhong Da Hospital, Southeast University School of Medicine, Nanjing, Jiangsu, China. 
${ }^{c}$ Institute of Nephrology, Taizhou Clinical Medical School of Nanjing Medical University (Taizhou People's Hospital), Taizhou, Jiangsu, China.

\section{Author contributions}

Bin Wang, Jing-yuan Cao: conceptualization, funding acquisition, project administration; Ming-ming Pan, Min Gao: resources, formal analysis, writing- original draft preparation; Jing-yuan Cao, Jing Zheng: writing- reviewing and editing; Ji-rong Yu: data curation; Sheng-chun Xu, Mei-xia Xia, Wen-jie Liu, Liu-ping Zhang: visualization, investigation; Xiao-liang Zhang, Bi-Cheng Liu: supervision.

\section{Author Declarations}

The authors declare that they have no competing interests with regard to any organization or entity with a financial interest in competition with the subject matter or materials discussed in this publication.

\section{Ethical Approval and Consent to participate}

The design of the present study was approved by the ethics committees of Zhongda Hospital, Southeast University School of Medicine was obtained before subject recruitment (2019ZDSYLL146-P01).

\section{Competing interests}

The authors declare that they have no competing interests in this paper.

\section{Acknowledgements and funding}

This work was supported by grants from the National Natural Science Foundation of China (82070735, 82100721) to Bin Wang and Jing-yuan Cao, and the Natural Science Foundation of Jiangsu Province (BK20181487) to Bin Wang, Foundation of Jiangsu Commission of health (H2019061) to Ming-ming Pan.

\section{Availability of data and materials}

The datasets used or analysed during the current study are available from the corresponding author on reasonable request.

\section{Consent for publication}

Not applicable

\section{References}

1. Kalantar-Zadeh K, Fouque D. Nutritional management of chronic kidney disease. N Engl J Med 2017, 377:1765-76. Doi:10.1056/NEJMra1700312. 
2. Sabatino A, Regolisti G, Karupaiah T, Sahathevan S, Sadu Singh BK, Khor BH, et al. Protein-energy wasting and nutritional supplementation in patients with end-stage renal disease on hemodialysis. Clin Nutr 2017, 36:663-71. Doi:10.1016/j.clnu.2016.06.007.

3. Ikizler TA, Cano NJ, Franch H, Fouque D, Himmelfarb J, Kalantar-Zadeh K, et al. Prevention and treatment of protein energy wasting in chronic kidney disease patients: a consensus statement by the International Society of Renal Nutrition and Metabolism. Kidney Int 2013, 84:1096-107. Doi:10.1038/ki.2013.147.

4. Burrowes JD, Cockram DB, Dwyer JT, Larive B, Paranandi L, Bergen C, et al. Cross-sectional relationship between dietary protein and energy intake, nutritional status, functional status, and comorbidity in older versus younger hemodialysis patients. J Ren Nutr 2002, 12:87-95. Doi:10.1053/jren.2002.32209.

5. Araújo IC, Kamimura MA, Draibe SA, Canziani ME, Manfredi SR, Avesani CM, et al. Nutritional parameters and mortality in incident hemodialysis patients. J Ren Nutr 2006, 16:27-35. Doi:10.1053/j.jrn.2005.10.003.

6. Cobo G, Lindholm B, Stenvinkel P. Chronic inflammation in end-stage renal disease and dialysis. Nephrol Dial Transplant 2018, 33:iii35-40. Doi.org/10.1093/ndt/gfy175.

7. Akchurin OM, Kaskel F. Update on inflammation in chronic kidney disease. Blood Purif 2015, 39:8492. Doi.org/10.1159/000368940.

8. Cohen-Cesla T, Azar A, Hamad RA, Shapiro G, Stav K, Efrati S, et al. Usual nutritional scores have acceptable sensitivity and specificity for diagnosing malnutrition compared to GLIM criteria in hemodialysis patients. Nutr Res 2021, 92:129-38. Doi:10.1016/j.nutres.2021.06.007.

9. Obi Y, Qader H, Kovesdy CP, Kalantar-Zadeh K. Latest consensus and update on protein-energy wasting in chronic kidney disease. Curr Opin Clin Nutr Metab Care 2015, 18:254-62. Doi:10.1097/mco.0000000000000171.

10. Fiaccadori E, Sabatino A, Barazzoni R, Carrero JJ, Cupisti A, De Waele E, et al. ESPEN guideline on clinical nutrition in hospitalized patients with acute or chronic kidney disease. Clin Nutr 2021, 40:1644-68. Doi:10.1016/j.clnu.2021.01.028.

11. Jeong JH, Biruete A, Tomayko EJ, Wu PT, Fitschen P, Chung HR, et al. Results from the randomized controlled IHOPE trial suggest no effects of oral protein supplementation and exercise training on physical function in hemodialysis patients. Kidney Int 2019, 96:777-86.

Doi:10.1016/j.kint.2019.03.018.

12. Fouque D, McKenzie J, de Mutsert R, Azar R, Teta D, Plauth M, et al. Use of a renal-specific oral supplement by haemodialysis patients with low protein intake does not increase the need for phosphate binders and may prevent a decline in nutritional status and quality of life. Nephrol Dial Transplant 2008, 23:2902-10. Doi:10.1093/ndt/gfn131.

13. Stratton RJ, Bircher G, Fouque D, Stenvinkel P, de Mutsert R, Engfer M, et al. Multinutrient oral supplements and tube feeding in maintenance dialysis: a systematic review and meta-analysis. Am J Kidney Dis 2005, 46:387-405. Doi:10.1053/j.ajkd.2005.04.036. 
14. Yang Y, Qin X, Chen J, Wang Q, Kong Y, Wan Q, et al. The effects of oral energy-dense supplements on nutritional status in nondiabetic maintenance hemodialysis patients: A randomized controlled trial. Clin J Am Soc Nephrol 2021, 16:1228-36. Doi:10.2215/cjn.16821020.

15. Zha Y, Qian Q. Protein nutrition and malnutrition in CKD and ESRD. Nutrients 2017, 27;9(3):208. Doi:10.3390/nu9030208.

16. Dhondup T, Qian Q. Electrolyte and acid-base disorders in chronic kidney disease and end-stage kidney failure. Blood Purif 2017, 43:179-88. Doi:10.1159/000452725.

17. Kalantar-Zadeh K, Cano NJ, Budde K, Chazot C, Kovesdy CP, Mak RH, et al. Diets and enteral supplements for improving outcomes in chronic kidney disease. Nat Rev Nephrol 2011, 7:369-84. Doi:10.1038/nrneph.2011.60.

18. Dehghan M, Mente A, Zhang X, Swaminathan S, Li W, Mohan V, et al. Associations of fats and carbohydrate intake with cardiovascular disease and mortality in 18 countries from five continents (PURE): a prospective cohort study. Lancet 2017, 390:2050-62. Doi:10.1016/s0140-6736(17)322523.

19. Carrero JJ, Stenvinkel P, Cuppari L, Ikizler TA, Kalantar-Zadeh K, Kaysen G, et al. Etiology of the protein-energy wasting syndrome in chronic kidney disease: a consensus statement from the International Society of Renal Nutrition and Metabolism (ISRNM). J Ren Nutr 2013, 23:77-90. Doi:10.1053/j.jrn.2013.01.001.

20. Kang SS, Chang JW, Park Y. Nutritional status predicts 10-year mortality in patients with end-stage renal disease on hemodialysis. Nutrients 2017, 18;9(4):399. Doi:10.3390/nu9040399.

21. Rezeq HA, Khdair LN, Hamdan ZI, Sweileh WM. Prevalence of malnutrition in hemodialysis patients: A single-center study in Palestine. Saudi J Kidney Dis Transpl 2018, 29:332-40. Doi:10.4103/13192442.229264.

22. Ikizler TA: A patient with CKD and poor nutritional status. Clin J Am Soc Nephrol 2013, 8:2174-82. Doi:10.2215/cjn.04630513.

23. Bonanni A, Mannucci I, Verzola D, Sofia A, Saffioti S, Gianetta E, et al. Protein-energy wasting and mortality in chronic kidney disease. Int J Environ Res Public Health 2011, 8:1631-54. Doi:10.3390/ijerph8051631.

24. Kalantar-Zadeh K, Kilpatrick RD, Kuwae N, McAllister CJ, Alcorn H, Jr., Kopple JD, et al. Revisiting mortality predictability of serum albumin in the dialysis population: time dependency, longitudinal changes and population-attributable fraction. Nephrol Dial Transplant 2005, 20:1880-8. Doi:10.1093/ndt/gfh941.

25. Walther CP, Gutiérrez OM, Cushman M, Judd SE, Lang J, McClellan W, et al. Serum albumin concentration and risk of end-stage renal disease: the REGARDS study. Nephrol Dial Transplant 2018, 33:1770-7. Doi:10.1093/ndt/gfx331.

26. Vervloet MG, van Ballegooijen AJ: Prevention and treatment of hyperphosphatemia in chronic kidney disease. Kidney Int 2018, 93:1060-72. Doi:10.1016/j.kint.2017.11.036. 
27. Voelkl J, Lang F, Eckardt KU, Amann K, Kuro OM, Pasch A, et al. Signaling pathways involved in vascular smooth muscle cell calcification during hyperphosphatemia. Cell Mol Life Sci 2019, 76:2077-91. Doi:10.1007/s00018-019-03054-z.

28. Yamada S, Tokumoto M, Tatsumoto N, Taniguchi M, Noguchi H, Nakano T, et al. Phosphate overload directly induces systemic inflammation and malnutrition as well as vascular calcification in uremia. Am J Physiol Renal Physiol 2014, 306:F1418-28. Doi:10.1152/ajprenal.00633.2013.

29. Delano MJ, Moldawer LL. The origins of cachexia in acute and chronic inflammatory diseases. Nutr Clin Pract 2006, 21:68-81. Doi:10.1177/011542650602100168.

30. Maraj M, Kuśnierz-Cabala B, Dumnicka P, Gala-Błądzińska A, Gawlik K, Pawlica-Gosiewska D, et al. Malnutrition, inflammation, atherosclerosis syndrome (MIA) and diet recommendations among endstage renal disease patients treated with maintenance hemodialysis. Nutrients 2018, 11;10(1):69.Doi:10.3390/nu10010069.

31. Wang $\mathrm{M}, \mathrm{Xu} \mathrm{H}$, Chong Lee Shin OL, Li L, Gao H, Zhao Z, et al. Compound a-keto acid tablet supplementation alleviates chronic kidney disease progression via inhibition of the NF-kB and MAPK pathways. J Transl Med 2019, 17:122. Doi:10.1186/s12967-019-1856-9.

32. Li K, Huang T, Zheng J, Wu K, Li D. Effect of marine-derived n-3 polyunsaturated fatty acids on Creactive protein, interleukin 6 and tumor necrosis factor a: a meta-analysis. PLoS One 2014, 9:e88103. Doi:10.1371/journal.pone.0088103.

33. Lemos JR, Alencastro MG, Konrath AV, Cargnin M, Manfro RC. Flaxseed oil supplementation decreases C-reactive protein levels in chronic hemodialysis patients. Nutr Res 2012, 32:921-7. Doi:10.1016/j.nutres.2012.08.007.

34. Stosovic M, Stanojevic M, Simic-Ogrizovic S, Jovanovic D, Djukanovic L. The predictive value of anthropometric parameters on mortality in haemodialysis patients. Nephrol Dial Transplant 2011, 26:1367-74. Doi:10.1093/ndt/gfq497.

35. Cabezas-Rodriguez I, Carrero JJ, Zoccali C, Qureshi AR, Ketteler M, Floege J, et al. Influence of body mass index on the association of weight changes with mortality in hemodialysis patients. Clin $\mathrm{J} \mathrm{Am}$ Soc Nephrol 2013, 8:1725-33. Doi:10.2215/cjn.10951012.

36. Park J, Ahmadi SF, Streja E, Molnar MZ, Flegal KM, Gillen D, et al. Obesity paradox in end-stage kidney disease patients. Prog Cardiovasc Dis 2014, 56:415-25. Doi:10.1016/j.pcad.2013.10.005.

\section{Figures}



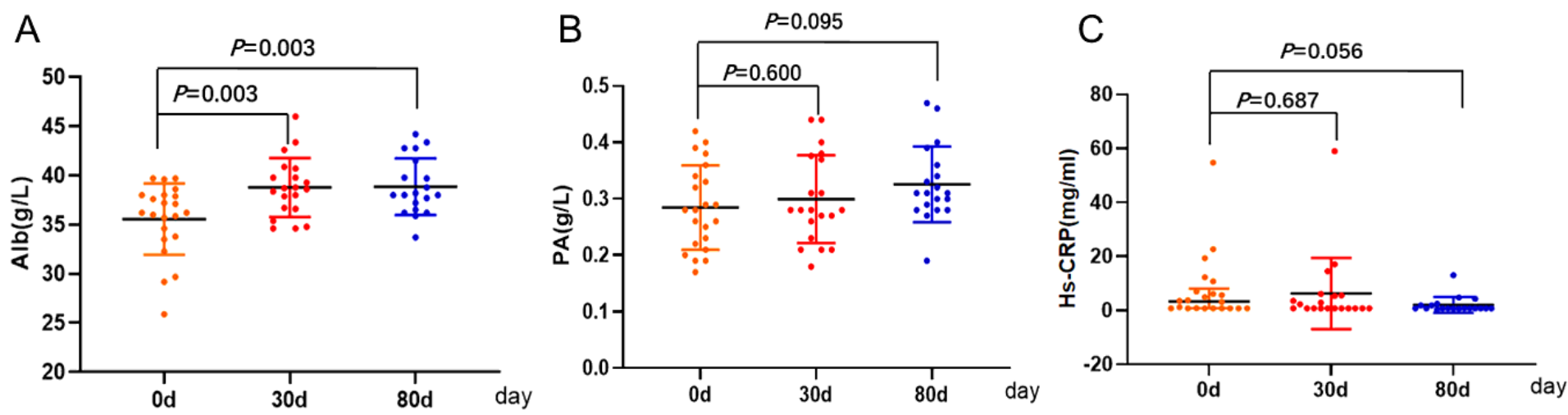

Figure 1

Flowchart of study participants for the study.

Adult MHD participants from our hemodialysis center
August 2019 to December, 2019
\[ (n=378) \]

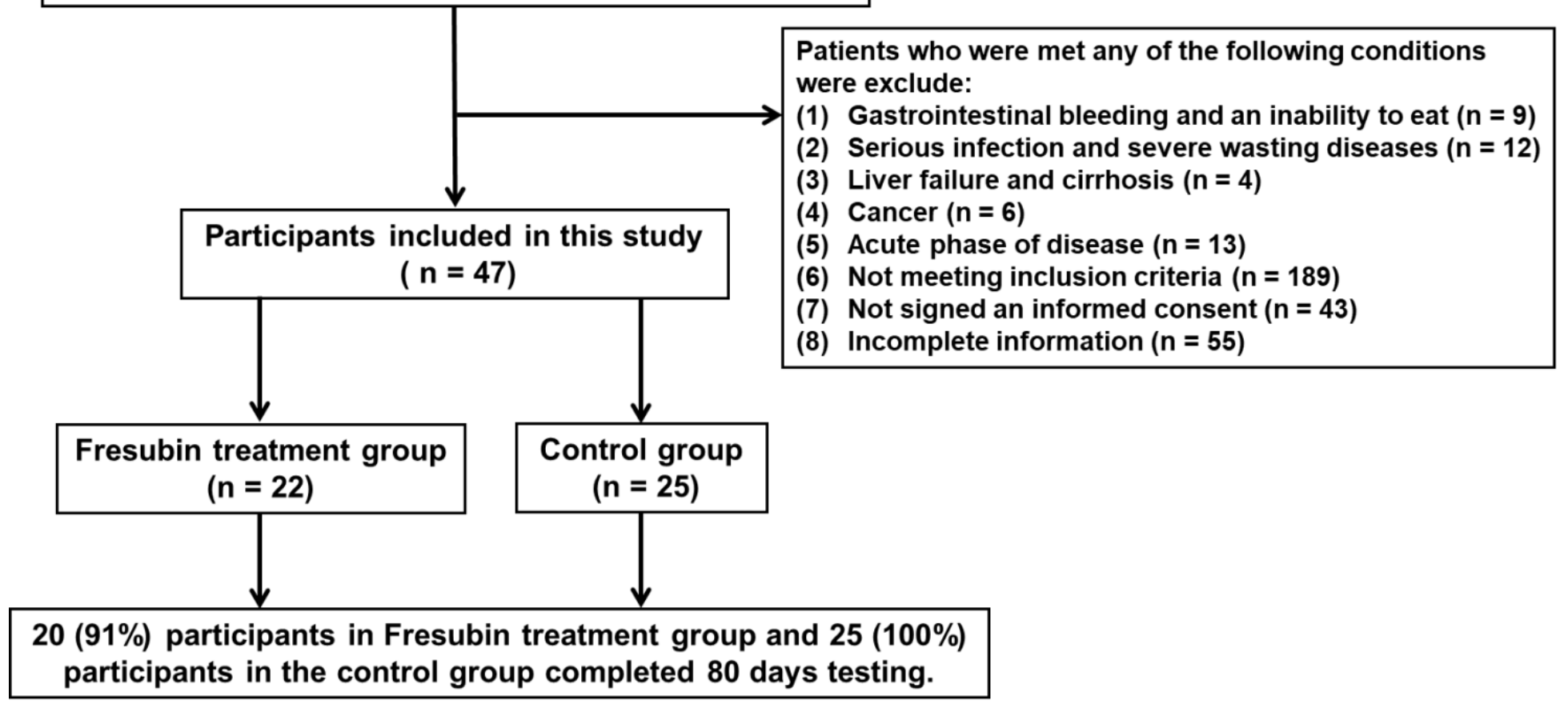

Figure 2

The data of patients (Alb, PA, Hs-CRP) in Fresubin treatment group on 0, 30 and 80days. (A)Alb level during the study in Fresubin treatment group. (B) PA level during the study in Fresubin treatment group. (C) Hs-CRP level during the study in Fresubin treatment group. 